\title{
BMJ Open Trends in the prevalence of airflow limitation in a general Japanese population: two serial cross-sectional surveys from the Hisayama Study
}

\author{
Hiroaki Ogata, ${ }^{1,2}$ Yoichiro Hirakawa, ${ }^{2,3}$ Koichiro Matsumoto, ${ }^{1}$ Jun Hata, ${ }^{2,3}$ \\ Daigo Yoshida, ${ }^{2}$ Satoru Fukuyama, ${ }^{1}$ Hiromasa Inoue, ${ }^{4}$ Takanari Kitazono, ${ }^{3}$ \\ Toshiharu Ninomiya, ${ }^{2}$ Yoichi Nakanishi ${ }^{1}$
}

To cite: Ogata H, Hirakawa Y, Matsumoto $\mathrm{K}$, et al. Trends in the prevalence of airflow limitation in a general Japanese population: two serial crosssectional surveys from the Hisayama Study. BMJ Open 2019;9:e023673. doi:10.1136/ bmjopen-2018-023673

- Prepublication history and additional material for this paper are available online. To view these files, please visit the journal online (http://dx.doi org/10.1136/bmjopen-2018023673).

Received 18 April 2018 Revised 12 September 2018 Accepted 28 November 2018

Check for updates

(C) Author(s) (or their employer(s)) 2019. Re-use permitted under CC BY-NC. No commercial re-use. See rights and permissions. Published by BMJ.

For numbered affiliations see end of article.

Correspondence to Dr Yoichiro Hirakawa; you1@eph.med.kyushu-u.ac.jp

\section{ABSTRACT}

Objectives Chronic obstructive airway disease, which is characterised by airflow limitation, is a major burden on public health. Reductions in environmental pollution in the atmosphere and workplace and a decline in the prevalence of smoking over recent decades may have affected the prevalence of airflow limitation in Japan. The present epidemiological study aimed to evaluate trends in the prevalence of airflow limitation and in the influence of risk factors on airflow limitation in a Japanese community. Design Two serial cross-sectional surveys.

Setting Data from the Hisayama Study, a populationbased prospective study that has been longitudinally conducted since 1961.

Participants A total of 1842 and 3033 residents aged $\geq 40$ years with proper spirometric measurements participated in the 1967 and 2012 surveys, respectively.

Main outcome measures Airflow limitation was defined as forced expiratory volume in $1 \mathrm{~s} /$ forced vital capacity $<70 \%$ by spirometry. For each survey, the age-adjusted prevalence of airflow limitation was evaluated by sex. ORs and population attributable fractions of risk factors on the presence of airflow limitation were compared between surveys.

Results The age-standardised prevalence of airflow limitation decreased from 1967 to 2012 in both sexes (from $26.3 \%$ to $16.1 \%$ in men and from $19.8 \%$ to $10.5 \%$ in women). Smoking was significantly associated with higher likelihood of airflow limitation in both surveys, although the magnitude of its influence was greater in 2012 than in 1967 (the multivariable-adjusted OR was $1.63(95 \% \mathrm{Cl} 1.19$ to 2.24$)$ in 1967 and $2.26(95 \% \mathrm{Cl} 1.72$ to 2.99 ) in 2012; $p=0.007$ for heterogeneity). Accordingly, the population attributable fraction of smoking on airflow limitation was $33.5 \%$ in 2012, which was 1.5-fold higher than that in 1967 (21.1\%).

Conclusions The prevalence of airflow limitation was decreased over 45 years in Japan, but the influence of smoking on airflow limitation increased with time.

\section{INTRODUCTION}

Chronic obstructive pulmonary disease (COPD), which is characterised by persistent
Strengths and limitations of this study

- The strengths of our study include the high participation rates and the use of spirometry for evaluating the exact prevalence of airflow limitation in both 1967 and 2012 surveys.

- One limitation was the difference in the instruments used for spirometry: a dry wedge bellows spirometer in 1967 versus a more sophisticated instrument in 2012.

- Another limitation was the possible decrease in airflow limitation due to the bronchodilators that have been used as standard therapies for chronic obstructive pulmonary disease and asthma over the last decade in our country.

respiratory symptoms and airflow limitation defined by postbronchodilator spirometry, is a major threat to the health of the respiratory system. COPD is composed of a mixture of small airway disease (eg, obstructive bronchiolitis) and parenchymal destruction (emphysema) and can lead to acute exacerbation of respiratory symptoms and airway function, ultimately progressing to respiratory failure. ${ }^{1}$ In addition, COPD poses a great burden in terms of morbidity and premature mortality as well as in healthcare expenditures worldwide. ${ }^{2}$ Prebronchodilator airflow limitation, which include chronic obstructive ventilatory disorders such as COPD, asthma and bronchiectasis, is a well-used outcome in the epidemiological study without postbronchodilator spirometry. Therefore, it would be clinically and epidemiologically valuable to clarify the trends in the prevalence of airflow limitation and in the influence of risk factors on airflow limitation in individual communities.

A previous literature-based meta-analysis estimated that the prevalence of airflow limitation increased over two decades in both 
developed and developing regions, but these estimations were based on a statistical model. ${ }^{3}$ Few studies have addressed the trends in the prevalence of airflow limitation over time based on the data from repeated community-based surveys, although the nationwide surveys in the USA showed a decreasing trend in the prevalence of airflow limitation. ${ }^{4}$ Tobacco smoke, indoor and outdoor air pollutants and occupational dust have been acknowledged as major risk factors for airflow limitation along with genetic factors such as alpha, ${ }_{1}$-antitrypsin deficiency, ${ }^{5}$ but there has been no survey assessing the associations of risk factors with the prevalence of airflow limitation in a time series manner. In recent decades, reduction of environmental pollution in the atmosphere and workplace and the reduction in smoking prevalence ${ }^{6-10}$ may have affected the influence of these risk factors on airflow limitation.

The purpose of the present study was to evaluate trends in the prevalence of airflow limitation in Japan from 1967 to 2012 using two serial cross-sectional surveys concerning different generations from a long-term community-based study, the Hisayama Study, with high participation rates and a consistent spirometric definition of airflow limitation. In addition, the magnitudes of the association of risk factors with airflow limitation were compared between surveys.

\section{METHODS}

\section{Study population}

Since 1961, a population-based prospective study has been longitudinally conducted to investigate the distributions and associations of lifestyle-related diseases and their risk factors in the town of Hisayama, Japan. Details of this cohort study have been described elsewhere. ${ }^{11}$ As part of an annual health examination, two serial cross-sectional surveys of airflow limitation with spirometry were performed in 1967 and 2012. In 1967, a total of 1973 residents aged $\geq 40$ years $(88.0 \%$ of the whole population in this age group) consented to participate in an examination and underwent a comprehensive health assessment. Among them, 129 subjects who were either unable or unwilling to submit to a measurement of pulmonary function and 2 subjects in whom spirometric measurements were performed incorrectly were excluded. The remaining 1842 subjects (824 men and 1018 women) with successfully measured pulmonary function were enrolled in the present study. Similarly, in 2012, 3396 subjects participated in a health examination (participation rate: 72.6\%). After excluding six subjects who refused to participate in the epidemiological research and 357 subjects who were either unable or unwilling to submit to spirometric measurement, 3033 subjects (1340 men and 1693 women) with proper spirometric measurements were enrolled in the study (online supplementary figure E1).

\section{Assessment and definition of airflow limitation}

A dry wedge bellows spirometer was used in 1967 to obtain volume-time curves. Participants underwent spirometry several times until valid curves were obtained. Pulmonary physicians graphically evaluated and scrutinised the figures and obtained the values of forced expiratory volume in $1 \mathrm{~s}\left(\mathrm{FEV}_{1}\right)$, forced vital capacity (FVC) and $\mathrm{FEV}_{1} / \mathrm{FVC}$. In the 2012 survey, spirometry was performed in line with the guidelines of the Japanese Respiratory Society (JRS) ${ }^{12}$ Two to four measurements were performed using a CHESTGRAPH HI-105 electronic spirometer (Chest MI, Tokyo), in order to obtain satisfactory flow-volume loops. Pulmonary physicians visually assessed the quality of the manoeuvres and chose the finest loop, showing the highest sum of $\mathrm{FEV}_{1}$ and FVC. FVC, $\mathrm{FEV}_{1}$ and $\mathrm{FEV}_{1} / \mathrm{FVC}$ were obtained from the selected curve. Bronchodilators were not used for any of the surveys.

Airflow limitation was pathophysiologically assessed with spirometry and without any radiological measurements or clinical symptoms. There are two major worldwide criteria for the definition of airflow limitation: the modified Global Initiative for Chronic Obstructive Lung Disease (GOLD) criteria with a fixed cut-off of $\mathrm{FEV}_{1} / \mathrm{FVC}^{13}$ and the American Thoracic Society/European Respiratory Society (ATS/ERS) criteria using age-specific, sex-specific and height-specific lower limits of normal (LLNs) for the cut-off of $\mathrm{FEV}_{1} / \mathrm{FVC}^{14}$ We employed both the GOLD criteria and the ATS/ERS criteria. When calculating LLN, we used the reference equations for the Japanese population that were reported by the Clinical Pulmonary Functions Committee of the JRS in 2014. ${ }^{15}$ Those equations were derived using the lambda, mu and sigma method employed by the ERS Global Lung Function Initiative (GLI) Task Force, since the GLI reference group did not include Japanese subjects. ${ }^{15} 16$ The GOLD criteria-based airflow limitation was defined as $\mathrm{FEV}_{1} / \mathrm{FVC}<70 \%$. We also used a modified definition of airflow limitation (ie, $\mathrm{FEV}_{1} / \mathrm{FVC}<67 \%$ ), because the dry wedge bellows spirometer has been reported to yield values $2 \%-3 \%$ lower than those measured by a water-sealed spirometer or an electronic spirometer. ${ }^{17} 18$ Among participants with airflow limitation, the severity was defined using the predicted $\mathrm{FEV}_{1}$ value for a person of the same age, sex and height using the equation for the Japanese population ${ }^{15}$ as follows: mild: $\mathrm{FEV}_{1} \geq 80 \%$ of predicted; moderate: $50 \% \leq \mathrm{FEV}_{1}<80 \%$ of predicted; severe and very severe: $\mathrm{FEV}_{1}<50 \%$ of predicted. The ATS/ERS criteria-based airflow limitation was defined as $\mathrm{FEV}_{1} / \mathrm{FVC}<$ the fifth percentile (LLN), and the severity of airflow limitation was defined as follows: mild: $\mathrm{FEV}_{1} \geq 70 \%$ predicted; moderate and moderately severe: $50 \% \leq \mathrm{FEV}_{1}<70 \%$ predicted; and severe and very severe: $\mathrm{FEV}_{1}<50 \%$ predicted. Regarding the ATS/ERS criteria-based airflow limitation, we also calculated LLN using the reference equations for the Japanese population that were reported by the ERS GLI Task Force in 2012. ${ }^{16}$

\section{Clinical evaluation and laboratory measurements}

Each participant completed a self-administered questionnaire covering smoking habits, alcohol intake, 
medical history and antihypertensive treatments. Smoking habits were categorised as never smokers or current/former smokers since airflow limitation could persist even after cessation of smoking. Alcohol drinking was defined as current or not. Body height and weight were measured in light clothing without shoes, and body mass index (BMI; $\mathrm{kg} / \mathrm{m}^{2}$ ) was calculated. Overweight and underweight were defined as BMI $\geq 25.0 \mathrm{~kg} /$ $\mathrm{m}^{2}$ and BMI $<18.5 \mathrm{~kg} / \mathrm{m}^{2}$, respectively. Blood pressure was measured three times using a mercury sphygmomanometer in 1967 and an automated sphygmomanometer (BP-203 RVIIIB; Omron Healthcare, Kyoto) in 2012 in a sitting position after rest for at least $5 \mathrm{~min}$; the average values were used in the analyses. Hypertension was defined as a systolic blood pressure $\geq 140 \mathrm{~mm} \mathrm{Hg}$, a diastolic blood pressure $\geq 90 \mathrm{~mm} \mathrm{Hg}$ or current treatment with antihypertensive agents.

\section{Statistical analysis}

The SAS software package V.9.4 was used to perform all statistical analyses. Baseline characteristics were shown as age-adjusted values by sex and by survey year using the analysis of covariance (ANCOVA) for continuous variables or by the direct method using the age distribution of the 1985 Japanese population as a standard. ${ }^{19}$ They were compared between survey years using an ANCOVA, a Cochran-Mantel-Haenszel test or a logistic regression model. The sex-specific prevalence of airflow limitation was estimated separately for each age group (40-49, 50-59, 60-69 and 70+ years) and as a whole adjusting for age by the direct method using the same standard population. The linear trend of airflow limitation across age groups in each survey year was tested using a logistic regression model. The same model was used for the test of secular trends in sex-specific and age-standardised prevalence of airflow limitation from 1967 to 2012. Among residents with airflow limitation, the sex-specific and age-standardised distribution of its severity was compared between survey years using an ordinal logistic regression model. The associations of potential risk factors with airflow limitation were estimated as adjusted ORs with 95\% CIs for each survey year by using multivariable-adjusted logistic regression models, wherein adjustment was made for sex, age, smoking habits, overweight, underweight, hypertension and living alone that were associated with airflow limitation or COPD in previous reports. ${ }^{13}$ 20-22 Multivariable-adjusted ORs with 95\% CIs were calculated using data of subjects with no missing data (proportion of subjects excluded: $2.1 \%$ in 1967 and $0.07 \%$ in 2012). We tested whether these associations were changed over decades by including the interactions of risk factors and the survey years in the relevant statistical models. The contribution of each risk factor to airflow limitation was estimated as a population attributable fraction (PAF) in each survey using the multivariable-adjusted OR of each risk factor and its frequency among cases ${ }^{23}$ which represents the proportional reduction in population that would occur if each risk factor was eliminated. The $95 \%$
CIs of the PAFs were estimated in accordance with Greenland's method. ${ }^{24}$

As described above, the analysis was also performed using the ATS/ERS criteria with the JRS or GLI reference equations for each survey year. Another sensitivity analysis was performed with the modified definition of airflow limitation, which was $\mathrm{FEV}_{1} / \mathrm{FVC}$ of $<67 \%$. A two-sided value of $\mathrm{p}<0.05$ was considered to indicate statistical significance.

\section{Participant involvement}

There was no direct patient involvement in the development, design or conduct of the study.

\section{Ethical considerations}

Written or oral informed consent was obtained from all the participants. In addition, we are applying an opt-out methodology to announce that the study is ongoing and to provide the opportunity of refusal through the official website according to the ethical guidelines for medical and health research involving human subjects in Japan. ${ }^{25}$

\section{RESULTS}

\section{Demographic and clinical characteristics}

The demographic and clinical characteristics in 1967 and 2012 are summarised by sex in table 1 , in which the mean values and the frequencies were adjusted for age. In both sexes, subjects in 2012 were older than those in 1967. The mean values of height, weight and BMI were higher in 2012 than 1967. The frequencies of drinking habits and living alone also increased over 45 years. The prevalence of hypertension decreased with time. For smoking habits (current or ever smoking), there was a downward trend in men and an upward trend in women, although the frequency of ever smokers significantly increased in both sexes (from $11.5 \%$ in 1967 to $44.1 \%$ in 2012 for men, and from $1.7 \%$ in 1967 to $11.6 \%$ in 2012 for women; $\mathrm{p}<0.001$ in both sexes).

\section{Trends in the prevalence of airflow limitation}

Among the 1842 and 3033 survey subjects in 1967 and 2012, 401 and 524 subjects had airflow limitation, respectively. The age-standardised prevalence decreased over the intervening decades (from $26.3 \%$ to $16.1 \%$ in men and $19.8 \%$ to $10.5 \%$ in women) (figure 1). Almost all age groups in both sexes, with the exception of 40-49 years in women, showed significant downward trends in the age-specific prevalence from 1967 to 2012 (figure 2). The prevalence of airflow limitation increased with age in both 1967 and 2012 (all $\mathrm{p}<0.001$ for trend). As shown in figure 3 , there was a significant shift in the distribution of severity of airflow limitation in both men and women with airflow limitation; the proportions of moderate and severe/very severe airflow limitation decreased over time, while the proportion of mild airflow limitation increased ( $p<0.001$ for difference in both sexes). The results of the analyses were not substantially changed according 
Table 1 Age-adjusted mean values or frequencies of demographic and clinical characteristics in 1967 and 2012 by sex

\begin{tabular}{|c|c|c|c|c|c|c|}
\hline \multirow[b]{2}{*}{ Variables } & \multicolumn{3}{|l|}{ Men } & \multicolumn{3}{|l|}{ Women } \\
\hline & $\begin{array}{l}1967 \\
(n=824)\end{array}$ & $\begin{array}{l}2012 \\
(n=1340)\end{array}$ & P value & $\begin{array}{l}1967 \\
(n=1018)\end{array}$ & $\begin{array}{l}2012 \\
(n=1693)\end{array}$ & $P$ value \\
\hline Height (cm) & $158(0.21)$ & $166(0.16)$ & $<0.001$ & $146(0.17)$ & $153(0.13)$ & $<0.001$ \\
\hline Weight (kg) & $53.2(0.32)$ & $65.8(0.25)$ & $<0.001$ & $47.4(0.27)$ & $53.6(0.21)$ & $<0.001$ \\
\hline Overweight (\%) & 7.6 & 31.5 & $<0.001$ & 17.0 & 22.0 & 0.001 \\
\hline Normal weight (\%) & 84.9 & 64.6 & & 72.4 & 67.6 & \\
\hline Underweight (\%) & 7.5 & 3.9 & & 10.6 & 10.5 & \\
\hline $\begin{array}{l}\text { Smoking habit } \\
\text { (current/ever) (\%) }\end{array}$ & 83.6 & 79.8 & 0.08 & 13.9 & 20.6 & 0.003 \\
\hline Ever smoker (\%) & 11.5 & 44.1 & $<0.001$ & 1.7 & 11.6 & $<0.001$ \\
\hline Alcohol intake (\%) & 63.3 & 74.7 & $<0.001$ & 4.1 & 40.1 & $<0.001$ \\
\hline Hypertension (\%) & 57.3 & 47.7 & $<0.001$ & 53.0 & 33.8 & $<0.001$ \\
\hline $\begin{array}{l}\text { Systolic blood } \\
\text { pressure }(\mathrm{mm} \mathrm{Hg})\end{array}$ & $147.0(0.78)$ & $130.7(0.61)$ & $<0.001$ & $145.7(0.65)$ & $125.4(0.50)$ & $<0.001$ \\
\hline $\begin{array}{l}\text { Diastolic blood } \\
\text { pressure }(\mathrm{mm} \mathrm{Hg})\end{array}$ & $86.4(0.44)$ & $79.8(0.34)$ & $<0.001$ & $83.8(0.37)$ & $74.0(0.28)$ & $<0.001$ \\
\hline $\begin{array}{l}\text { Antihypertensive } \\
\text { medication (\%) }\end{array}$ & 13.6 & 29.3 & $<0.001$ & 15.0 & 21.8 & $<0.001$ \\
\hline Living alone (\%) & 1.3 & 4.5 & $<0.001$ & 2.5 & 5.4 & 0.002 \\
\hline
\end{tabular}

Age is given as the mean plus SE. Other values are given as the age-adjusted mean (if appropriate) with SEs in brackets for continuous variables and as age-adjusted percentages for dichotomised or categorical variables. $P$ values denote the statistical significance of the difference in each variable between 1967 and 2012. Overweight was defined as a BMI $\geq 25.0 \mathrm{~kg} / \mathrm{m}^{2}$. Underweight was defined as a $\mathrm{BMI}<18.5 \mathrm{~kg} / \mathrm{m}^{2}$. Smoking habits were categorised as never smokers or current/former smokers. Alcohol intake was defined as current or not. Hypertension was defined as blood pressure $\geq 140 / 90 \mathrm{~mm} \mathrm{Hg}$ and/or current use of antihypertensive agents. Numbers of subjects with missing data were as follows: alcohol intake: 20, hypertension: 4, antihypertensive medication: 10 and living alone: 9 in men in 1967; living alone: 1 in men in 2012; smoking habit: 2, alcohol intake: 42, hypertension: 3, antihypertensive medication: 5 and living alone: 25 in women in 1967; no missing data in women in 2012.

BMI, body mass index.

to whether the ATS/ERS criteria with the JRS reference equations (online supplementary figure E2-4), the GLI reference equations (online supplementary figure E5-7) or the modified definition of airflow limitation (ie, $\mathrm{FEV}_{1}$ / FVC <67\%) from 1967 (online supplementary figure E8-10) was used.

\section{Trends in the associations of risk factors with airflow limitation}

There was a significant positive association of smoking with airflow limitation in both surveys $(\mathrm{OR}=1.63(95 \% \mathrm{CI}$ 1.19 to 2.24 ), $\mathrm{p}=0.003$ in 1967 ; $\mathrm{OR}=2.26$ (95\% CI 1.72 to 2.99), $\mathrm{p}<0.001$ in 2012) (figure 4). In comparison, there was a stronger association between smoking and airflow limitation in 2012 than in 1967 ( $\mathrm{p}=0.007$ for interaction). Consequently, the contribution of smoking to the estimated proportion of cases with airflow limitation-that is, PAF-was $21.1 \%$ in 1967 and $33.5 \%$ in 2012 (a 1.5-fold increase). Overweight was negatively associated with airflow limitation in both surveys $(\mathrm{OR}=0.65$ (95\% CI 0.42 to 0.98 ), $\mathrm{p}=0.04$ in 1967 ; $\mathrm{OR}=0.66$ (95\% CI 0.52 to 0.85 ), $\mathrm{p}=0.001$ in 2012), and there was no statistically significant difference between them ( $p=0.84$ for interaction). Nevertheless, due to the twofold elevation in the proportion of overweight from $13.0 \%$ in 1967 to $26.7 \%$ in 2012, the potential of overweight for reducing the proportion of airflow limitation (PAF) was greater in 2012 than in 1967 ( $-4.1 \%$ in 1967 to $-10.3 \%$ in 2012$)$. For the associations of sex (men vs women) with airflow limitation, we found a significant difference between survey years, although neither association reached statistical significance. The other variables were not associated with airflow limitation and made no significant contributions to the PAF. In the sex-specific analysis, the influence of each risk factor on airflow limitation was substantially similar between sexes 

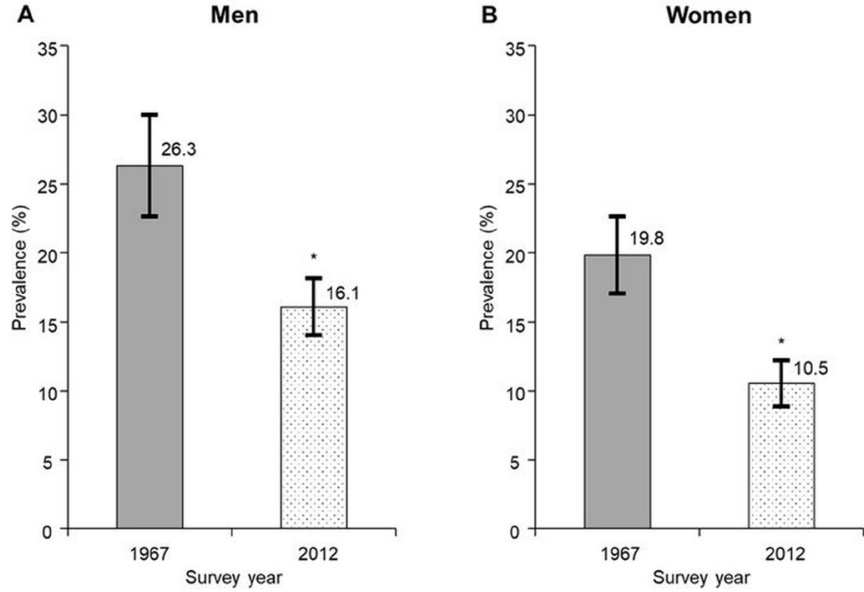

Figure 1 Trends in the age-adjusted prevalence of airflow limitation in 1967 and 2012 by sex. Vertical bars indicate 95\% Cls. ${ }^{*} \mathrm{P}<0.001$ versus 1967 . Airflow limitation was defined as forced expiratory volume in 1 s/forced vital capacity $<70 \%$ according to the Global Initiative for Chronic Obstructive Lung Disease criteria.

(all $\mathrm{p}>0.06$ for heterogeneity), except for underweight in 1967 ( $\mathrm{p}=0.002$ for heterogeneity) (online supplementary figure E11).

\section{DISCUSSION}

The present comparison of the prevalence of airflow limitation based on the GOLD criteria in Japan revealed a significant reduction from 1967 to 2012, consistently across age-groups in both men and women. Among participants with airflow limitation, the proportion with a moderate to severe level of the disorder decreased remarkably. Similar findings were observed with the ATS/ERS criteria. Moreover, both the relative association between smoking and airflow limitation and the PAF of smoking were compared and found to be stronger in 2012 than
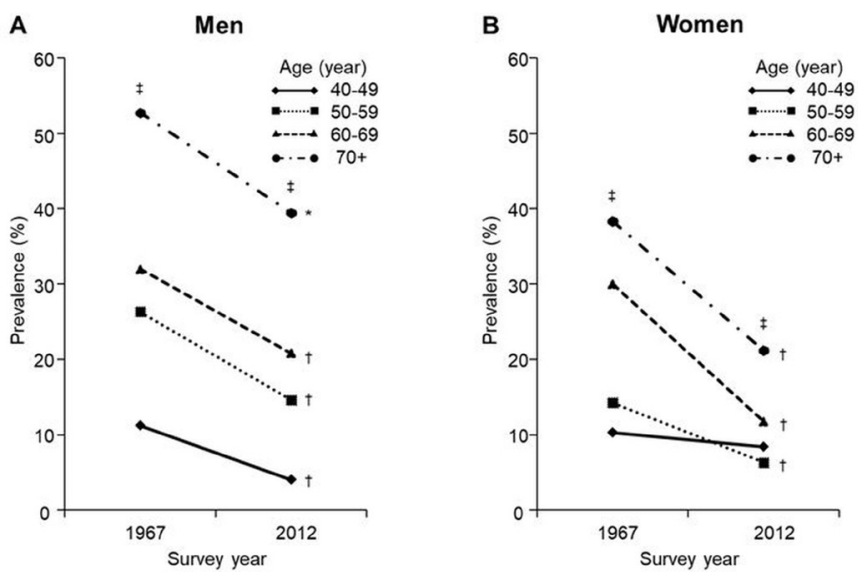

Figure 2 Trends in the prevalence of airflow limitation according to age groups in 1967 and 2012 by sex. ${ }^{*} \mathrm{P}<0.05$, ${ }^{\dagger} p<0.01$ versus $1967,{ }^{\ddagger} p$ for trend $<0.01$. Airflow limitation was defined as forced expiratory volume in $1 \mathrm{~s} /$ forced vital capacity $<70 \%$ according to the Global Initiative for Chronic Obstructive Lung Disease criteria.
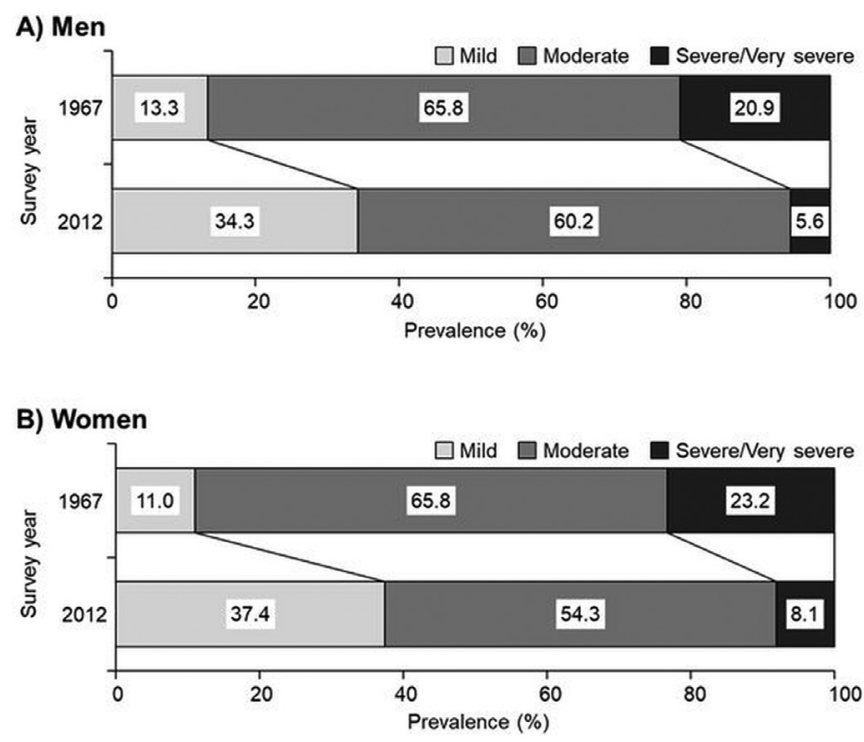

Figure 3 Trends in the age-adjusted prevalence of airflow limitation according to severity in 1967 and 2012 by sex. Airflow limitation was defined as forced expiratory volume in $1 \mathrm{~s} /$ forced vital capacity $<70 \%$ according to the Global Initiative for Chronic Obstructive Lung Disease criteria.

in 1967. This is the first study to evaluate trends in the prevalence of airflow limitation and in the influence of its risk factors in an Asian population on the basis of the data from repeated community-based surveys.

Epidemiological findings in regard to trends in the prevalence of airflow limitation are very limited. A literature-based meta-analysis of cross-sectional spirometric surveys showed that there was an increase in the prevalence of airflow limitation from the 1990s to 2010s in both developed and developing regions. ${ }^{3}$ However, these estimations were calculated by using a statistical model on the basis of demographic changes over time. However, the results from the repeated nationwide National Health and Nutrition Examination Surveys demonstrated that there was a significant decrease in the prevalence of airflow limitation in the USA from 1988-1994 to 20072010, although it barely changed from 1971-1975 to 1988-1994. ${ }^{46}$ This finding was in accord with ours. The reduction of environmental pollution in both the atmosphere and workplace and the reduction in the smoking frequency may have decreased the prevalence of airflow limitation in the USA as well as in our population. ${ }^{6-10}$

Previous studies estimated the prevalence of airflow limitation in Japan in the 2000s as $16.2 \%-16.4 \%$ among men and 5.0\%-5.8\% among women. ${ }^{27} 28$ The former range was similar to that in 2012 in the present study, while the latter was twofold lower. The discrepancy may be due to the difference in the participation rate, which would likely lead to a selection bias; the participation rate in our study was over threefold higher than those in the preceding studies. The prevalence of airflow limitation determined using the GOLD criteria has been reported to be higher than that based on the ATS/ERS criteria in elderly populations, ${ }^{429}$ which was consistent with our 


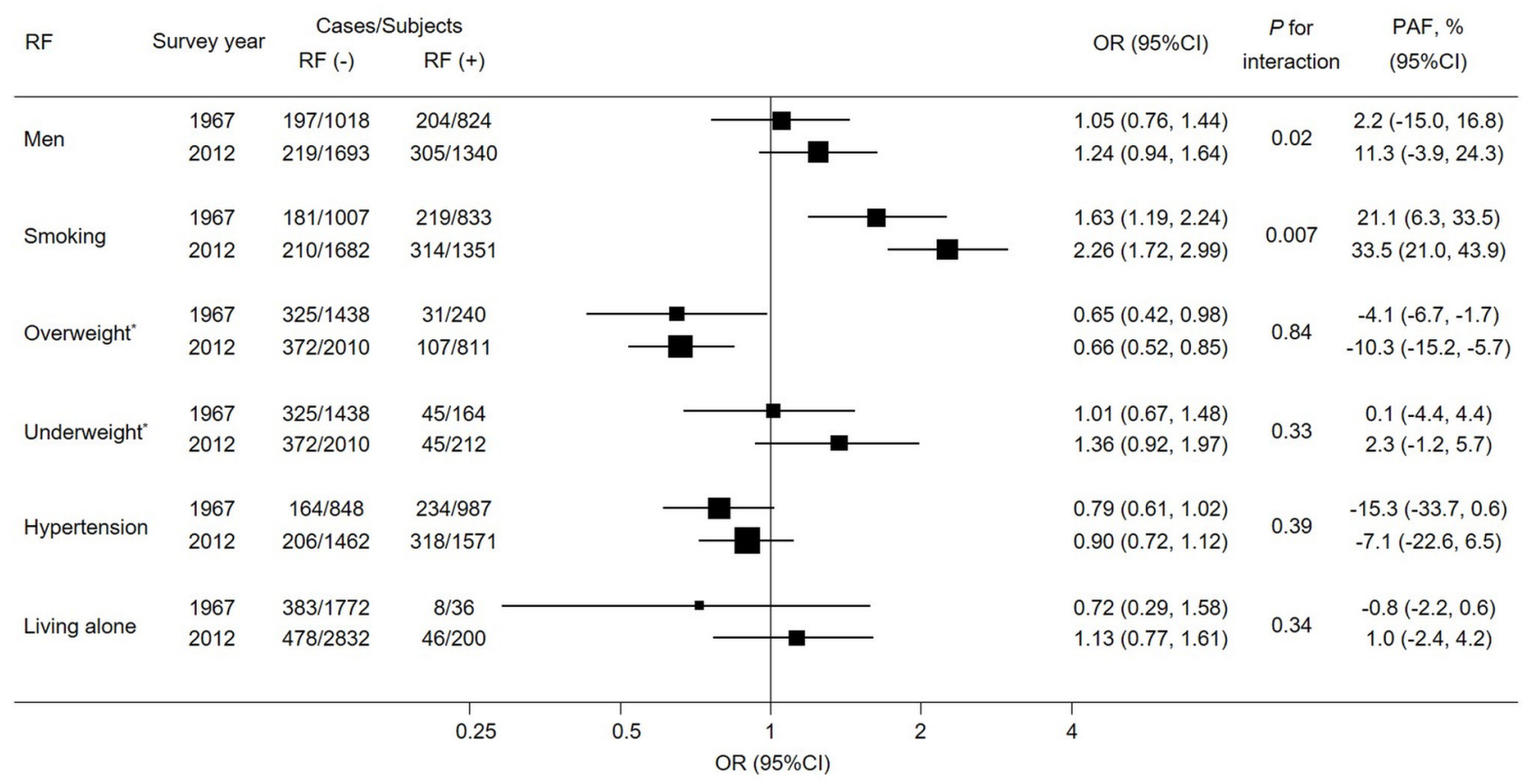

Figure 4 Multivariate-adjusted ORs and PAFs of risk factors for airflow limitation in 1967 and 2012. Airflow limitation was defined as forced expiratory volume in $1 \mathrm{~s}$ /forced vital capacity $<70 \%$. Adjustments were made for sex, age, smoking habits, overweight ${ }^{\star}$, underweight ${ }^{\star}$, hypertension and living alone. Horizontal bars indicate $95 \%$ Cls. ${ }^{*}$ For the analysis of overweight and underweight, the normal weight group was used as the reference group. PAF, population attributable fraction; RF, risk factor.

study. However, other than ours, there has been no study estimating the prevalence of airflow limitation in Japan using the ATS/ERS criteria, and thus further studies are needed.

In the present study, the potentiating effects of smoking on airflow limitation were more pronounced in 2012 than in 1967. Cigarette smoking and chronic inhalational exposure to a polluted atmosphere both lead to COPD by the same mechanism, that is, hazardous particles penetrating deep into the respiratory tract and eliciting neutrophilic inflammation and oxidative stress. ${ }^{30}$ However, environmental, occupational and household exposure to hazardous pollutants has been steadily attenuated over the last several decades. This reduction in exposure to atmospheric pollutants could have increased the relative influence of smoking in recent years. ${ }^{31}$ In turn, the prevention of tobacco use and the promotion of smoking cessation have become increasingly important public health concerns in order to prevent airflow limitation and COPD.

The present study showed that overweight was inversely associated with airflow limitation both in 1967 and 2012. Previous observational studies demonstrated that higher BMI was associated with lower FVC and therefore with higher $\mathrm{FEV}_{1} / \mathrm{FVC}^{20}{ }^{32}$ which probably reflected the decrease in excursion of the thoracic cage due to intra-abdominal and subpleural fat deposition. ${ }^{33}$ Our present findings may also be explained by reverse causality; weight loss commonly occurs in COPD patients via muscle wasting and elevated energy metabolism. ${ }^{21}$ The weaker association and smaller PAF among women than among men in 2012 can be explained by the relatively small number of female participants with airflow limitation. There was no evidence of a significant association between underweight and airflow limitation in either survey, but the influence of underweight on the airflow limitation was different between the sexes. The underlying explanation for this heterogeneity was unclear. It may merely reflect the play of chance.

In the present study, the magnitude of the association between male sex and the airflow limitation in 2012 was significantly greater than that in 1967 , although the OR for each survey did not reach statistical significance. This heterogeneity may have been caused by residual confounding due to the greater amount and duration of tobacco smoking in men than women, considering the fact that the influence of smoking habits increased with time, as mentioned above. Nevertheless, based on the current evidence, it remains controversial whether the male sex is a risk factor for airflow limitation. ${ }^{34-37}$ Further evaluation of this matter is warranted.

The strengths of our study include the high participation rates and the use of spirometry for evaluating the exact prevalence of airflow limitation in both surveys. However, some potential limitations should be noted. First, there was a difference in the instruments used for spirometry: a dry wedge bellows spirometer in 1967 versus a more sophisticated instrument in 2012. This limitation could have led to an overestimation of the prevalence of airflow limitation in 1967, since the dry wedge bellows spirometer has been reported to generate $2 \%-3 \%$ smaller $\mathrm{FEV} / \mathrm{FVC}$ values compared with the instrument used in 2012. ${ }^{17}$ However, several other studies have reported that the dry wedge bellows spirometer exhibited comparable 
reliability to more sophisticated instruments. ${ }^{38-41}$ Additionally, the sensitivity analyses using the $3 \%$ lower cut-off value for $\mathrm{FEV}_{1} / \mathrm{FVC}$ in 1967 showed similar results. Hence, this potential bias did not appear to have affected the present results. Second, there was a possibility of decrease in airflow limitation due to the bronchodilators, such as short-acting $\beta 2$ agonist, short-acting muscarinic antagonist, long-acting $\beta 2$ agonist (LABA), long-acting muscarinic antagonist (LAMA), inhaled corticosteroids/ LABA, LABA/LAMA and xanthine, that have been used as standard therapies for COPD and asthma over the last decade in our country. ${ }^{43}$ However, the proportion of subjects who used bronchodilators was only $2.6 \% \quad(n=80)$ in 2012, and thus the decrease in the prevalence of airflow limitation was unlikely by virtue of the effects of these medications. Third, we did not have access to a pulmonary function test with assessment of airflow reversibility or postbronchodilator $\mathrm{FEV}_{1} / \mathrm{FVC}$; some of the individuals with airflow limitation might have had chronic obstructive ventilatory disorders such as asthma rather than COPD. However, this limitation would not have changed our conclusion, because the prevalence of airflow limitation decreased in the present study despite the increasing trend in the prevalence of asthma in Japan. ${ }^{44}$ Fourth, airflow limitation could also include a restrictive ventilatory disorder associated with an obstructive disorder, such as combined pulmonary fibrosis and emphysema (CPFE). However, in a recent epidemiological study, subjects with CPFE were found to make up only $5 \%-10 \%$ of total COPD cases. ${ }^{45}$ Thus, this limitation may not have altered our conclusions. Fifth, airflow limitation could include several types of obstructive disorders, and thus we should be cautious about concluding that individual risk factors affect all of the diseases providing airflow limitation. Lastly, we were unable to investigate the effects of intensity or duration of smoking on airflow limitation due to lack of data concerning the number of pack years of cigarette smoking in 1967. However, in Japan, it has been reported that the number of cigarettes smoked per day has remained unchanged among smokers of both sexes (about 20 per day in men and about 15 per day in women) since the 1950s. ${ }^{46}$ In addition, the frequency of ever smokers who stopped smoking significantly increased in both sexes in the present study. Thus, we believe that the intensity or duration of smoking did not increase from 1967 to 2012.

In conclusion, over the past half century, the prevalence of airflow limitation that included COPD as well as other chronic obstructive ventilatory disorders has decreased significantly among the general Japanese population. However, more than $10 \%$ of men and women aged 40 years or older still exhibit airflow limitation. With respect to risk factors, the contribution of smoking to the occurrence of airflow limitation has become more pronounced over the previous five decades, which we speculated as a result of a reduction in the occupational exposures to indoor and outdoor air pollution. To accelerate the prevention of airflow limitation, therefore, further public efforts towards smoking cessation are mandatory.

\section{Author affiliations}

${ }^{1}$ Research Institute for Diseases of the Chest, Graduate School of Medical Sciences, Kyushu University, Fukuoka, Japan

${ }^{2}$ Department of Epidemiology and Public Health, Graduate School of Medical Sciences, Kyushu University, Fukuoka, Japan

${ }^{3}$ Department of Medicine and Clinical Science, Graduate School of Medical Sciences, Kyushu University, Fukuoka, Japan

${ }^{4}$ Department of Pulmonary Medicine, Graduate School of Medical and Dental Sciences, Kagoshima University, Kagoshima, Japan

Acknowledgements The authors would like to thank the residents of the town of Hisayama for their participation in the survey and the staff of the Division of Health and Welfare of Hisayama for their cooperation with this study.

Contributors $\mathrm{HO}$ contributed to the study concept, data collection, interpretation of data, statistical analysis and drafting of the manuscript. YH contributed to the study concept, data collection, interpretation of data and revision of the manuscript. SF and KM contributed to the data collection, interpretation of data and revision of the manuscript. JH, DY, HI, TK and YN contributed to interpretation of data and revision of the manuscript. TN was the chief investigator of the Hisayama Study and contributed to the study concept, data collection, interpretation of data, revision of the manuscript and acquisition of funding. All authors critically reviewed the manuscript and approved the final version.

Funding This study was supported in part by Grants-in-Aid for Scientific Research (A) (JP16H02644 and JP16H02692) and (B) (JP16H05850, JP16H05557 and JP17H04126) and (C) (JP15K09267, JP15K08738, JP15K09835, JP16K09244, JP17K09114, JP17K09113 and JP17K01853) from the Ministry of Education, Culture, Sports, Science and Technology of Japan; by Health and Labour Sciences Research Grants of the Ministry of Health, Labour and Welfare of Japan (H25-Junkankitou [Seishuu]-Sitei-022, H29-Junkankitou-Ippan-003 and H27-Shokuhin-[Sitei]-017); and by the Japan Agency for Medical Research and Development (JP17dk0207025, JP17ek0210082, JP17gm0610007, JP17ek0210083, JP17km0405202 and JP17ek0210080).

Competing interests $\mathrm{HI}$ reports grants from Astellas, AstraZeneca, BoehringerIngelheim, ChugaiPharm, GlaxoSmithKline, Pfizer, MerckSharp and Dohme, Novartis and Teijin-Pharma, personal fees from Astellas, AstraZeneca, BoehringerIngelheim, Chugai-Pharm, GlaxoSmithKline, Kyorin, MerckSharp and Dohme, MeijiSeikaPharma, Novartis, Otsuka, Pfizer, Taiho, outside the submitted work.

Patient consent for publication Not required.

Ethics approval The study was approved by the Kyushu University Institutional Review Board for Clinical Research.

Provenance and peer review Not commissioned; externally peer reviewed. Data sharing statement No additional data are available.

Open access This is an open access article distributed in accordance with the Creative Commons Attribution Non Commercial (CC BY-NC 4.0) license, which permits others to distribute, remix, adapt, build upon this work non-commercially, and license their derivative works on different terms, provided the original work is properly cited, appropriate credit is given, any changes made indicated, and the use is non-commercial. See: http://creativecommons.org/licenses/by-nc/4.0/.

\section{REFERENCES}

1. Vestbo J, Hurd SS, Agustí AG, et al. Global strategy for the diagnosis, management, and prevention of chronic obstructive pulmonary disease: GOLD executive summary. Am J Respir Crit Care Med 2013;187:347-65.

2. Mathers CD, Loncar D. Projections of global mortality and burden of disease from 2002 to 2030. PLoS Med 2006;3:e442-30.

3. Adeloye D, Chua S, Lee C, et al. Global and regional estimates of COPD prevalence: Systematic review and meta-analysis. J Glob Health 2015;5:20415.

4. Doney B, Hnizdo E, Dillon CF, et al. Prevalence of airflow obstruction in U.S. Adults Aged 40-79 Years: NHANES Data 1988-1994 and 2007-2010. COPD 2015;12:355-65.

5. Mannino DM, Buist AS. Global burden of COPD: risk factors, prevalence, and future trends. Lancet 2007;370:765-73. 
6. The Committee on Japan's Experience in the Battle Against Air Pollution. Japan's experience in the battle against air pollution: working towards sustainable development. Tokyo: The PollutionRelated Health Damage Compensation and Prevention Association, 1997.

7. World Health Organization. Indoor air pollution. http://www.who.int/ indoorair/en/ (Accessed 31 Oct 2017).

8. Bruce N, Perez-Padilla R, Albalak R. Indoor air pollution in developing countries: a major environmental and public health challenge. Bull World Health Organ 2000;78:1078-92.

9. Sakurai $\mathrm{H}$. Occupational safety and health in Japan: current situations and the future. Ind Health 2012;50:253-60.

10. Eriksen M, Mackay J, Schluger N, et al. The tobacco atlas. 5th edn. Atlanta: American Cancer Society, 2015.

11. Hata J, Ninomiya T, Hirakawa Y, et al. Secular trends in cardiovascular disease and its risk factors in Japanese: halfcentury data from the Hisayama Study (1961-2009). Circulation 2013;128:1198-205.

12. The Clinical Pulmonary Functions Committee of the Japanese Respiratory Society. Guidelines of respiratory function tests: spirometry, flow-volume curve, diffusion capacity of the lung [Article in Japanese. Tokyo: Japanese Respiratory Society, 2004.

13. Rabe KF, Hurd S, Anzueto A, et al. Global strategy for the diagnosis, management, and prevention of chronic obstructive pulmonary disease: GOLD executive summary. Am J Respir Crit Care Med 2007:176:532-55.

14. Pellegrino R, Viegi G, Brusasco V, et al. Interpretative strategies for lung function tests. Eur Respir J 2005;26:948-68.

15. Kubota M, Kobayashi H, Quanjer PH, et al. Reference values for spirometry, including vital capacity, in Japanese adults calculated with the LMS method and compared with previous values. Respir Investig 2014;52:242-50.

16. Quanjer PH, Stanojevic S, Cole TJ, et al. Multi-ethnic reference values for spirometry for the 3-95-yr age range: the global lung function 2012 equations. Eur Respir J 2012;40:1324-43.

17. Ledwith JW. Comparative spirometry measurements using a bellows-type and a water-sealed spirometer. Am Rev Respir Dis 1967;95:512-5.

18. Cox P, Miller L, Petty TL. Clinical evaluation of a new electronic spirometer. Chest 1973;63:517-9.

19. Statistics Bureau, Management and Coordination Agency. Results of the first basic complete tabulation, part 1, Japan: 1985 population census of Japan volume 2 [Article in Japanese. Tokyo: Statistics Bureau, Management and Coordination Agency, 1986.

20. Lazarus R, Sparrow D, Weiss ST. Effects of obesity and fat distribution on ventilatory function: the normative aging study. Chest 1997;111:891-8.

21. King DA, Cordova F, Scharf SM. Nutritional aspects of chronic obstructive pulmonary disease. Proc Am Thorac Soc 2008;5:519-23.

22. Noda T, Ojima T, Hayasaka S, et al. The health impact of remarriage behavior on chronic obstructive pulmonary disease: findings from the US longitudinal survey. BMC Public Health 2009;9:412.

23. Rockhill B, Newman B, Weinberg C. Use and misuse of population attributable fractions. Am J Public Health 1998;88:15-19.

24. Greenland S. Re: "Confidence limits made easy: interval estimation using a substitution method". Am J Epidemiol 1999;149:884.

25. Study H. Information for participants [in Japanese]. http://www. hisayama.med.kyushu-u.ac.jp/client/index.html (Accessed 21 Aug 2018).

26. Ford ES, Mannino DM, Zhao G, et al. Changes in mortality among US adults with COPD in two national cohorts recruited from 1971-1975 and 1988-1994. Chest 2012;141:101-10.
27. Fukuchi $Y$, Nishimura M, Ichinose M, et al. COPD in Japan: the Nippon COPD Epidemiology study. Respirology 2004;9:458-65.

28. Osaka D, Shibata Y, Abe S, et al. Relationship between habit of cigarette smoking and airflow limitation in healthy Japanese individuals: the Takahata study. Intern Med 2010;49:1489-99.

29. Swanney MP, Ruppel G, Enright PL, et al. Using the lower limit of normal for the $\mathrm{FEV}_{1} / \mathrm{FVC}$ ratio reduces the misclassification of airway obstruction. Thorax 2008;63:1046-51.

30. Traboulsi H, Guerrina N, lu M, et al. Inhaled pollutants: the molecular scene behind respiratory and systemic diseases associated with ultrafine particulate matter. Int $\mathrm{J} \mathrm{Mol} \mathrm{Sci}$ 2017; $18: 243$.

31. Eisner MD, Anthonisen N, Coultas D, et al. An official american thoracic society public policy statement: novel risk factors and the global burden of chronic obstructive pulmonary disease. Am J Respir Crit Care Med 2010;182:693-718.

32. Sin DD, Jones RL, Man SF. Obesity is a risk factor for dyspnea but not for airflow obstruction. Arch Intern Med 2002;162:1477-81.

33. Littleton SW. Impact of obesity on respiratory function. Respirology 2012;17:43-9.

34. Kim DS, Kim YS, Jung KS, et al. Prevalence of chronic obstructive pulmonary disease in Korea: a population-based spirometry survey. Am J Respir Crit Care Med 2005:172:842-7.

35. Silverman EK, Weiss ST, Drazen JM, et al. Gender-related differences in severe, early-onset chronic obstructive pulmonary disease. $A m \mathrm{~J}$ Respir Crit Care Med 2000;162:2152-8.

36. Bridevaux PO, Probst-Hensch NM, Schindler C, et al. Prevalence of airflow obstruction in smokers and never-smokers in Switzerland. Eur Respir J 2010;36:1259-69.

37. Lopez Varela MV, Montes de Oca M, Halbert RJ, et al. Sex-related differences in COPD in five Latin American cities: the PLATINO study. Eur Respir J 2010;36:1034-41.

38. WANG RI, Shipley RE. Simple instrument for evaluating pulmonary ventilatory function. J Am Med Assoc 1958;167:1730-3.

39. Horton GE, Phillips S. The expiratory ventilagram: application of total and timed vital capacities and maximal expiratory flow rate, as obtained by a bellows apparatus, for bedside and office use. Am Rev Respir Dis 1959;80:724-31.

40. Wang CS, Boyington DG, Krumholz RA. Comparison of spirometry measurements using McKesson vitalor and Collins spirometer. Dis Chest 1969;55:258-60.

41. Tajima Y. Standard values of pulmonary ventilatory capacity in Japanese. II. Usefulness of the Vitalor. Fukushima J Med Sci 1967; 14:111-8

42. The Committee for the Fourth Edition of the COPD Guidelines of the Japanese Respiratory Society. Guidelines for the diagnosis and treatment of COPD (chronic obstructive pulmonary disease). 4th edn. Tokyo: Japanese Respiratory Society, 2013.

43. Ichinose $\mathrm{M}$, Sugiura $\mathrm{H}$, Nagase $\mathrm{H}$, et al. Japanese guidelines for adult asthma 2017. Allergol Int 2017;66:163-89.

44. Fukutomi $\mathrm{Y}$, Taniguchi M, Watanabe J, et al. Time trend in the prevalence of adult asthma in Japan: findings from populationbased surveys in Fujieda City in 1985, 1999, and 2006. Allergol Int 2011;60:443-8.

45. Washko GR, Lynch DA, Matsuoka S, et al. Identification of early interstitial lung disease in smokers from the COPDGene Study. Acad Radiol 2010;17:48-53.

46. Forey B, Hamling J, Hamling J, et al. International smoking statistics web edition: Japan. London: P N Lee Statistics and Computing Ltd, 2016. 